\title{
The Role of Electromyograms in Resolving Musculoskeletal Interactions in Able-Bodied and Disabled Human Individuals
}

\author{
J. Mizrahi \\ Department of Biomedical Engineering \\ Technion, Israel Institute of Technology, Haifa \\ Israel
}

\section{Introduction}

Electromyography (EMG) is a significant indicator of muscle activity and constitutes a fundamental and important tool in the fields of biomechanics, kinesiology and exercise physiology. Clinically, it serves for diagnosis and treatment monitoring. However, the raw signal obtained from the EMG of a muscle is difficult to interpret without the application of appropriate signal processing techniques. If processed in the time domain, the envelope of the rectified EMG signal may serve, with further processing, for several applications including: indication of muscle activity (Rakos et al, 1999), or estimation of force (Genadry et al, 1988). If processed in the frequency domain, EMG may point to the development of muscle fatigue (De Luca, 1997; Mizrahi et al, 2001). The electromyographic signal may also be used as a bio-control signal in conjunction with bio-assistive motion (Langzam et al 2006a, 2007; Mizrahi et al 1994; Peasgood et al, 2000; Saxena et al 1995; Thorsen et al, 1999).

This Chapter deals with the role of electromyography in facilitating the biomechanical solutions of musculo-skeletal systems characterized by neuro-muscular indeterminacies.

\section{Neuro-muscular redundancy and mechanical indeterminacy}

A major and interesting question in human biomechanics and kinesiology is how many muscles are required for performing a given motor task? Not less intriguing is the question relating to the number of muscles actually engaged in performing this given motor task. Past work on human locomotion has demonstrated that, if we take level walking as an example, no less than 31 muscle groups are engaged in each leg. Electromyograms of the major muscles of the leg during locomotion have been used to show the sequence of muscle activation in the gait cycles (Bechtol 1975; Mizrahi 2004). The multi-muscle performance of the walking task involves patterns of timings and intensities necessitating central control to be provided by the central nervous system. For instance, the knee and ankle extensors must 'switch-on' their activity near heel-strike, and remain partly active in the mid-stance and swing phases, and much less so in the other phases of the gait cycle. It is the multi-muscle sequencing of this large-scale system that provides the smooth, graceful, motion of walking. In analogy, somewhat similar sequencing can be found in an orchestral score of a multiinstrument musical composition, such as a symphony or opera, assigning the temporal roles 
of the different musical instruments (Mizrahi, 2004). Here too, there is a need for a central control which in this case is provided by the orchestra's conductor.

It may be argued, though, that the involvement of all the muscles in the abovementioned walking task is not essential and that the locomotor system is neuro-muscularly redundant, with substantially more acting muscle groups than actually required. Mechanically, the consequence of this redundancy is that the number of unknown internal joint and muscle forces exceeds the number of mechanical equations, rendering the system mechanically indeterminate.

The origin of the abovementioned neuro-muscular redundancy can be found in the descending pathways from the central nervous system to the peripheral nervous system. As a matter of fact, there exist multiple pathways for the performance of a given motor task such that the same information may be processed in different ways. Thus, a given central command may result in different activations and, conversely, different commands can result in the same activation. A trivial example is presented in Figure 1, illustrating how a torque of required intensity at a joint can be provided. It is evident that this torque can be produced in an infinite number of ways, involving the possible co-activation of the antagonist muscles with various contraction intensities. From the purely mechanical aspect, such co-activation is actually undesirable because it results in an increased net joint force. Nevertheless, coactivation is physiologically beneficial because it facilitates stability and controllability of posture and motion.

In summary, indeterminacy occurs wherever the number of unknowns exceeds the number of available biomechanical equations. Indeterminacy is associated with a multitude of possible solutions of the available system of equations. Conventional methods of addressing mechanical indeterminacy usually refer to the implementation of optimization criteria (Patriarco et al, 1981) providing supplementary equations that allow eliminating inadequate solutions. The level of indeterminacy is expected to decrease with the reduction of redundancy. Particularly here information from electromyograms may become instrumental in resolving muscle and joint forces as well as other unknowns from the musculo-skeletal mechanical equations.

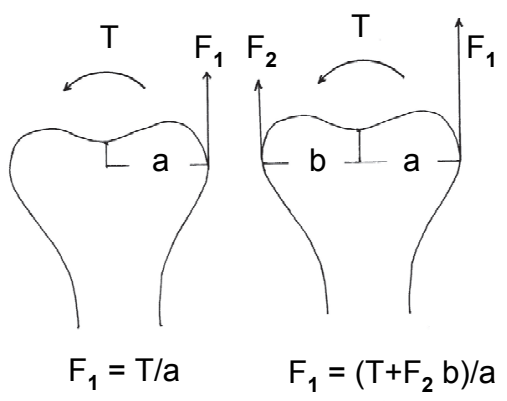

(a)

(b)

Fig. 1. Illustration of how a required torque $T$ at a joint can be applied in multiple ways: (a) by means of the agonist only $F_{1 ;}(\mathrm{b})$ by means of various co-activations of the agonist $F_{1}$ and the antagonist $F_{2}$. Note that in case (b) both $F_{1}$ and the resulting joint force are larger than in case (a). 


\section{Circumstances where neuro-muscular redundancy may diminish}

Neuro-muscular redundancy may get reduced under several circumstances, including the following:

(a) Grouping together of neighboring muscles which share a cooperative action about a joint, referred to as Muscle Synergy. An example of muscle synergy can be seen in cycling motion, as shown in Figure 2, where the sequence of muscle activation of four of the major muscle groups of the lower leg is shown by means of their raw Electromyograms. Cycling motion has been acknowledged as a significant rehabilitation modality for neurologically impaired subjects (Peng et al, 2011). The sequence of muscle action, as well as the patterns of the timings and intensities of the muscles is clearly noticed. Cycling is a smaller-scale motion-system compared to walking and the musical analogy can be demonstrated here by the score of one of Mozart's string quartets, indicating the assignment of the temporal roles of each of the four string instruments (Figure 2). The role of electromyograms in resolving joint dynamics in the context of muscle synergy is elaborated in Section 4.

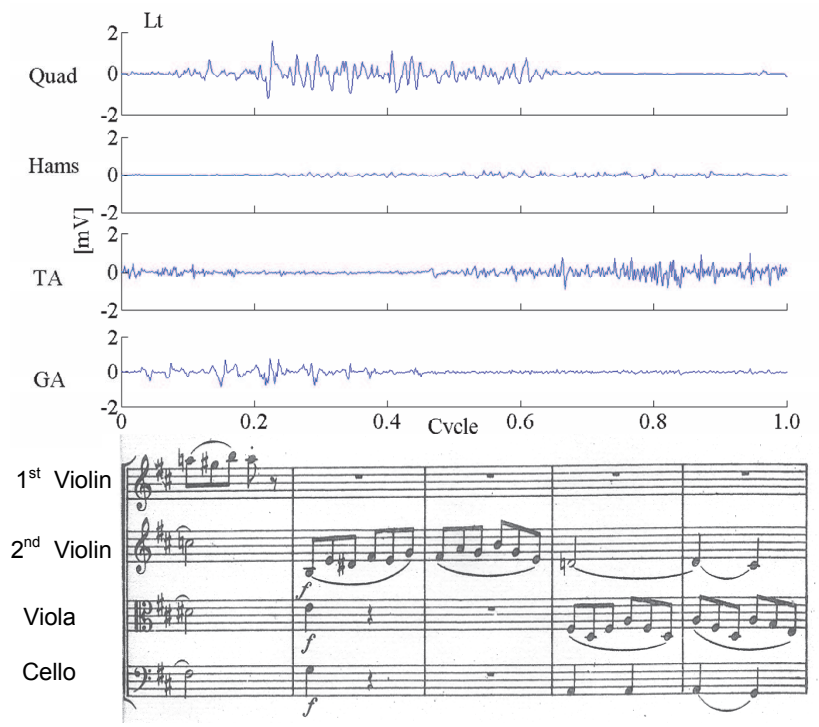

Fig. 2. Sequence of muscle activation during cycling motion of four of the major muscle groups of the left lower limb, including Quadriceps (Quad), Hamstrings (Hams), Tibialis Anterior (TA) and Gastrocnemius (GA). A musical analogy is shown in the lower part of the Figure by means of a line from one of Mozart's string quartets (in D major K 499, last movement). The analogy refers to the assignment of the temporal roles of each of the four string instruments versus sequencing of muscle action and patterns of timings and intensities of the muscle groups.

(b) Reducing redundancy through the volitional, deliberate, and selective exclusion of part of the musculo-skeletal system from being actively involved in the mechanical task. An example of the intentional abstention to utilize part of the body structures or actuators is noticed when standing on one leg only (as compared to two). This issue is further elaborated in Section 5. 
(c) Short-term neuro-muscular deficiency, such as during muscle Fatigue. This issue is dealt with in Sections 4 \& 5.

(d) Long-term, or permanent, neuro-musculo-skeletal deficiency, such as weakness, paralysis and the like. In the extreme case of paraplegia, when the fully paralyzed quadriceps muscle is activated by external electrical stimulation, this muscle becomes under conditions of low spasticity the only active muscle in the lower limb. Under these conditions redundancy is entirely eliminated and, consequently, the musculo-mechanical system becomes determinate allowing us to resolve the actual muscle force from the externally measured torque (Giat et al, 1993). However, in case of partial deficiency, although not entirely eliminated, redundancy becomes reduced. The issue of partial deficiency is elaborated in Section 6.

\section{Muscle synergy}

Under what conditions can one possibly correlate the torque about a joint, as indicated by the electromyograms of the actuating muscles, with the kinematics of that joint? This question was specifically dealt with by Russek (2002) in the Lab of the present author. The work focused on the utilization of the myoelectric signals from the Gastrocnemius and Tibialis Anterior antagonists to estimate ankle kinematics. These specific muscles were previously reported to adequately serve for the prediction of ankle torque (Cavanagh, 1990; Prilutsky et al 1998).

The paradigm used by Russek (2002).was of running on a level treadmill for a total period of $30 \mathrm{~min}$ at a running speed just exceeding the anaerobic threshold (average $\sim 3.5 \mathrm{~m} / \mathrm{s}$ ). EMG data of the Tibialis Anterior and Gastrocnemius muscles were online collected, simultaneously with the kinematics of the lower limb, as obtained from video data. The above-selected values of running speed and duration allowed, in addition, monitoring the effect of progressing fatigue on the EMG/kinematics relations. The EMG signals were bandpass filtered with a $10^{\text {th }}$ order Butterworth filter with a cut-off frequency of $10-500 \mathrm{~Hz}$ (De Luca 1997; Oppenheim \& Schafer 1975), in order to eliminate noise and artifacts, due to leg movement and muscle contraction, and sampled at $1667 \mathrm{~Hz}$. Since the EMG signal was nonstationary during long periods of data, it was segmented into short epochs of widestationary cycles (Bendat \& Piersol, 1970), corresponding to the running cycle.

The foot-strike event points were obtained from the signals of an accelerometer attached at the tibial tuberosity of the running subjects. Since the exact timing of the foot strike point could not be estimated directly from the video data due to its low sampling rate $(50 \mathrm{~Hz})$, the accelerometer signal was taken to indicate the peak of the foot strike. The foot-strike point was set to precede the peak acceleration by $30 \mathrm{~ms}$ (Daily, 1998). The toe-off event points were obtained from the repetitive Gastrocnemius signal, using an algorithm that identifies the periods of muscular activity (Marple-Horvat \& Gilbey, 1992). The kinematic data were smoothed with a $4^{\text {th }}$ order Butterworth low-pass filter with a cut frequency of $10 \mathrm{~Hz}$ (Bourdin et al, 1995; Prilutsky et al, 1998). To address the problem of different sampling frequencies between EMG and kinematical data, low-pass interpolation was used by inserting zeros into the original sequence and then applying a special symmetric Finite Impulse Response low-pass filter (IEEE, 1979).

\subsection{Analysis}

The analysis presented is for general dynamic conditions, thus extending previous analyses done under either isokinetic or isotonic conditions (Colson et al, 1999; Kellis\& Baltzopoulos, 
1998; Tamaki et al 1997,). The foot segment is assumed to move under general plane motion in the sagittal plane. The moments about the center of gravity thus involve the reaction forces at the ankle joint and the foot-ground contact, as well as the net joint torque about the ankle due to the co-contraction of the Tibialis Anterior and Gastrocnemius muscles. At first, a proportionality relation between the net actuating ankle torque and the angular acceleration of the foot segment is sought. This may, however, involve an error, reflecting the absence of torques of the reactive forces; this error will be later dealt with. Since the torques of the muscles can be represented by their respective EMG signals, the proportionality relation will, after time-integration, read as follows:

$$
K_{G} \cdot i E M G_{G}-K_{T} \cdot i E M G_{T} \propto \Delta \omega_{A}
$$

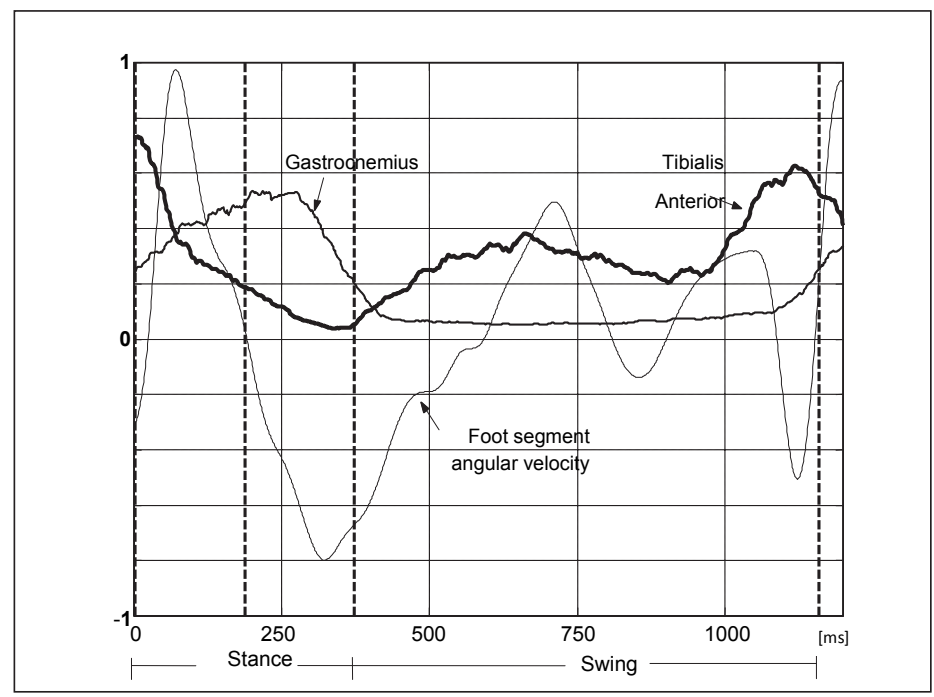

Fig. 3. One running-cycle illustration of the smoothed, rectified, EMG signals of the Gastrocnemius and Tibialis Anterior and of the ankle angular velocity (normalized units on vertical axis), segmented into three sections (separated by dashed vertical lines), namely: 1) first part of stance, 2) second part of stance, and 3) swing phase.

Where $i E M G$ denotes the integrated EMG, with the subscript denoting the Gastrocnemius $(G)$ or Tibialis Anterior $(T)$ muscle, $\Delta \omega_{A}$ is the change of angular velocity of the foot segment and the $K$ 's are respective coefficients. The proportionality (1) can be turned into an equation by modifying these coefficients as follows:

$$
\hat{K}_{G} \cdot i E M G_{G}-\hat{K}_{T} \cdot i E M G_{T} \cong \Delta \omega_{A}
$$

Since the EMG signals of the Tibialis Anterior and Gastrocnemius muscles, as well as the angular velocity, are actually measured (as demonstrated in Figure 3), the coefficients $\hat{K}$ 's in equation (2) can be obtained using parameter estimation methods. Rewriting, in a more general form, yields 


$$
\begin{gathered}
\overline{\hat{K}} \cdot \overline{\overline{i E M G}}=\overline{\Delta \omega_{A}} \\
\text { where } \quad \overline{\Delta \omega}_{A}=\left[\Delta \omega_{A 1}, \Delta \omega_{A 2} \ldots . \Delta \omega_{A m}\right]
\end{gathered}
$$

and

$$
\begin{aligned}
\overline{\overline{i E M G}}= & {\left[\begin{array}{ll}
i E M G_{G 1}, & -i E M G_{T 1} \\
i E M G_{G 2}, & -i E M G_{T 2} \\
\vdots \\
i E M G_{G m}, & -i E M G_{T m}
\end{array}\right] } \\
& \overline{\hat{K}}=\left[\begin{array}{ll}
\hat{K}_{G}, & \hat{K}_{T}
\end{array}\right]
\end{aligned}
$$

$m=1,2 . .$, number of running cycles during the time of data acquisition.

The earlier mentioned error $\bar{e}$ is

$$
\bar{e}=\overline{\Delta \omega_{A}}-\overline{\hat{K}} \cdot \overline{\overline{i E M G}}
$$

And the sum of the residual square is expressed as:

$$
\varphi_{O L S}=\sum e^{-2}=\left(\overline{\Delta \omega}_{A}-\overline{\hat{K}} \cdot \overline{\overline{i E M G}}\right)^{T}\left(\overline{\Delta \omega}_{A}-\overline{\hat{K}} \cdot \overline{\overline{i E M G}}\right)
$$

Using least-square methods, the vector $\overline{\hat{K}}$ can be calculated. It is convenient to express the separate coefficients as the respective co-activation ratios, as follows:

$$
\hat{K}_{G}[\%]=\hat{K}_{G} /\left(\hat{K}_{G}+\hat{K}_{T}\right) \cdot 100 \% \text { and } \hat{K}_{T}[\%]=\hat{K}_{T} /\left(\hat{K}_{G}+\hat{K}_{T}\right) \cdot 100 \%
$$

Substantial changes in the EMG signals take place within each running cycle. To account for these changes, the analysis was divided into segments. Previous studies used to divide the EMG signal into stance and swing phase of the entire stride cycle (Buczek \& Cavanagh, 1990; Nilsson et al, 1985; Prilutsky et al, 1998). In view of the observed changes in muscular activity of both the Gastrocnemius and the Tibialis Anterior within the stance phase, it was decided to further divide the stance phase into two segments (corresponding to eccentric and concentric activities, respectively) giving altogether three segments for the running cycle. The weight coefficients $\hat{K}_{G}$ and $\hat{K}_{T}$ were estimated as indicators of muscular activity of the Gastrocnemius and Tibialis Anterior, respectively. Especially, they served as cocontraction indicators in the first part of the stance phase.

\subsection{Coefficients of muscle activity and change in angular velocity}

The estimation values, summarized in Table 1, indicate that in the first-stance section coactivation of the Gastrocnemius and Tibialis Anterior muscles prevails (57\% and 43\%, respectively). In the second-stance section the Gastrocnemius muscle becomes clearly dominant (79\%, versus $21 \%$ for the T muscle) and in the swing section the opposite is seen, with nearly $90 \%$ for the Tibialis Anterior muscle and 10\% for the Gastrocnemius muscle. It 
should be noted, though, that before the foot-strike, during the late part of the swing phase, the ankle performed dorsiflexion, preparing for the touch down to the ground, while the Tibialis Anterior muscle had the highest muscular activity.

\begin{tabular}{|c|c|c|c|}
\hline & \multicolumn{3}{|c|}{ Running time (min) } \\
\cline { 2 - 4 } & 1 & 15 & 30 \\
\cline { 2 - 4 } & & & \\
\hline First-stance phase & & & \\
\hline (Foot strike- Mid stance) & 56.99 & 69.11 & $73.84^{* *}$ \\
& $(12.48)$ & $(11.53)$ & $(15.43)$ \\
\hline Second-stance phase & 79.38 & 79.77 & 84.02 \\
(Mid stance - Toe off) & $(12.53)$ & $(13.18)$ & $(12.62)$ \\
\hline Swing phase & 10.45 & 7.89 & 6.43 \\
Toe off - Foot strike & $(5.89)$ & $(4.92)$ & $(5.38)$ \\
& & & \\
\hline
\end{tabular}

${ }^{*} \hat{K}_{T}[\%]=100-\hat{K}_{G}[\%] ; * * p<0.05$

Table 1. Summary of the estimated weight coefficients $\hat{K}_{G}$ and $\hat{K}_{T}{ }^{*}$ (expressed in \%) for the three phases of the running cycle and for the $1^{\text {st }}, 15^{\text {th }}$ and $30^{\text {th }}$ min of level running. Means (SD) are given. Double asterisks $\left({ }^{* *}\right)$ denote a significant difference compared to the first minute of running $(p<0.05)$ as a result of fatigue.

The high Gastrocnemius muscular activity in the second part of the stance phase was accompanied by an elevated plantar-flexion, as the ankle joint decelerated until the final part of the second stance section, indicating a rapid generation of energy to propel the limb upward and forward (Winter \& Scott, 1991). The significant increase in the Tibialis Anterior muscle activity during the swing phase is required for ankle dorsiflexion as this joint begins to accelerate. Later in the swing phase the Tibialis Anterior supports the foot against gravity and prepares for the heel contact.

Using the obtained EMG weight coefficients, the change in angular velocity $\Delta \omega_{A}$ was calculated and compared to that actually measured. The results of this comparison indicated that the two quantities were closely similar with a proximity coefficient (using Pearson correlation) of 0.998 and up for each of the three cycle sections.

\subsection{Fatiguing effect}

Following fatiguing after $30 \mathrm{~min}$ of running at a speed exceeding the anaerobic threshold, the coefficient $\hat{K}_{G n}$ increased in the stance phase and decreased in the swing phase, although this change was significant $(\mathrm{p}<0.05)$ in the first-stance (eccentric) phase only. The effect of fatiguing was thus noticed in the first part of the stance phase, and as mentioned above; this phase is characterized by co-activation of the two antagonist muscles. However, due to progressing fatigue, there was a significant increase of the Gastrocnemius coefficient with a parallel decrease of the Tibialis Anterior coefficient from the first to the thirtieth minute of running $(p=0.024)$. The increasingly higher Gastrocnemius activity was required 
in order to change from dorsi- to plantar-flexion and to decelerate the angular ankle velocity.

\section{Intentional reduction of redundancy}

A fundamental difficulty in biomechanics is that the internal muscle and joint forces cannot be directly and non-invasively measured. More easily accessible measurements include the external loads and EMG's of the major limb muscles. However, as a consequence of the neuro-muscular redundancy and the resulting biomechanical indeterminacy, these EMG signals cannot be readily and simply correlated to the external loads acting on the human body. This Section demonstrates how, in cases where the neuro-muscular redundancy of the system can be reduced, the EMG signals may become more correlated to the externally measured reactive foot-ground forces. The paradigm used here is the regulation of balance during quiet standing in the upright position.

\subsection{The regularly redundant case}

Balance regulation while maintaining the standing-still posture is achieved by the interplay between body sway motion and the external forces acting on the swaying body. These include, apart from the gravitational force, the foot-ground reaction forces (Levin \& Mizrahi 1996; Levin et al, 1998; Mizrahi et al, 2002; Mizrahi \& Susak, 1982). Balance regulation is made possible by the continuous activity of the leg and lower trunk muscles. An obvious question, therefore, is whether the activity of these muscles, as monitored by their electromyograms (EMG), correlates to the external forces involved in the regulation of balance. If correlated, to what extent? An additional question is whether reduced redundancy modifies the extent of correlation and makes EMG and ground reaction forces become more correlated? With bi-pedal or double-stance standing as the reference posture, this question was studied by successively removing redundancies from the neuro-musculoskeletal system.

\subsection{Successive reduction of neuro-muscular redundancies}

The first stage is to substitute the normal pi-pedal or double-stance case by single-stance standing. In single-leg standing, the musculo-skeletal system responsible for postural control has been reported to be less redundant than in double-leg standing (Levin et al, 2000a). In this posture, the standing body is acted upon by the reactive forces from one leg only and the task of balance regulation is performed by activation of the muscles of this leg, resulting in a smaller number of muscles actively engaged in stabilizing the standing posture. Further reduction of redundancy may be achieved by eliminating visual feedback, i.e. with the eyes closed, as opposed to eyes open.

Standing posture experiments, as reported from the lab of the present Author (Levin \& Mizrahi, 1996; Levin et al, 1998; Levin et al, 2000a; Suponitsky et al, 2008), performed simultaneous on-line measurements of ground reaction forces and EMG's of the leg's major muscle groups for double- and single-stance standing. The double-stance standing experiments were for $30 \mathrm{~s}$ and the duration of the single-stance was for as long as the tested subject was able to maintain balance equilibrium.

The acquired force-plate and raw EMG signals were de-trended to compensate for longterm drift and their DC levels were set to zero. Each signal vector was then divided into epochs of $1 \mathrm{~s}$ for which the root mean square were calculated. The 1-s root mean square and 
values of the myoelectric activity were correlated with the corresponding root mean square values of the force plate data, using the Pearson's correlation coefficient with the significance level set at $p<0.05$. Differences between the standing positions were tested for the mean values of the force plate and EMG results by using the student's t-test (statistical significance set at the 0.05 level).

The comparisons between double- and single-stance standing are demonstrated in Tables 2 \& 3 which summarize, respectively, results for the foot-ground reactions forces and the myoelectric activity of the four major muscle groups. It is evident that in single-stance standing there is a substantial increase in force and muscle activity compared to doublestance standing. The reactive forces (Table 2) are described in terms of their three components: anterior-posterior, medial-lateral and vertical. The vertical values represent fluctuations ('ac' component) about the baseline ('dc' component) of the force beneath the supporting leg. An increased force activity and center-of-pressure (COP) excursion is noticed in single-stance compared to double-stance standing. The EMG signals of four of the major muscles are summarized in Table 3. Like with the reactive forces, an increased muscle activity is noticed in single-stance compared to double-stance standing.

\begin{tabular}{|c|c|c|c|}
\hline & & \multicolumn{2}{|c|}{ RMS } \\
\hline & & Double stance & Single stance \\
\hline \multirow{2}{*}{$\begin{array}{c}\text { Force } \\
{[\mathrm{N}]}\end{array}$} & Anterior-posterior & $0.6(0.2)$ & $2.5(1.0)^{*}$ \\
\cline { 2 - 4 } & Medial-lateral & $0.6(0.2)$ & $3.6(2.0)^{*}$ \\
\cline { 2 - 4 } & Vertical & $4.5(1.1)$ & $6.3(3.5)^{*}$ \\
\hline $\begin{array}{c}\text { Center of } \\
\text { pressure } \\
{[\mathrm{cm}]}\end{array}$ & Anterior-posterior & $0.3(0.1)$ & $0.6(0.2)^{*}$ \\
\cline { 2 - 4 } & Medial-lateral & $0.2(0.3)$ & $0.6(0.1)^{*}$ \\
\hline
\end{tabular}

Table 2. Average (SD) of the root-mean-square (RMS, time domain) of the foot ground reaction forces. *significant differences $(p<0.05)$ between single stance and double stance

\begin{tabular}{|c|c|c|}
\hline \multirow{2}{*}{ EMG } & \multicolumn{2}{|c|}{ RMS [\%MVC] } \\
\cline { 2 - 3 } & Double stance & Single stance \\
\hline Tibialis Anterior & $3.5(3.6)$ & $26(20)^{*}$ \\
\hline Gastrocnemius & $8.4(8.8)$ & $58(32)^{*}$ \\
\hline Quadriceps & $1.2(1.0)$ & $8(3.5)^{*}$ \\
\hline $\begin{array}{c}\text { Gluteus } \\
\text { Maximus }\end{array}$ & $3.4(2.0)$ & $11(8)^{*}$ \\
\hline
\end{tabular}

Table 3. EMG of the major leg muscles presented in Averages (SD) of the root mean square (RMS, time domain). The EMG RMS is expressed as percentage of the maximum voluntary contraction (\%MVC). The asterisk *denotes significant differences $(p<0.05)$ between single stance and double stance.

\subsection{Force/EMG correlations}

Regarding the correlation between foot-ground reaction forces and muscle activity, Figure 4 displays a comparison of the occurrence of significant correlation between the foot-ground reaction forces and the EMG of three of the leg major muscles (both expressed by means of their root mean squares): Tibialis Anterior, Quadriceps and Gluteus Maximus. Each of these 
muscles is correlated with the foot-ground reaction forces and COP components, as indicated in the Figure. It is noticed that the correlation patterns between foot-ground reaction forces and EMG strongly depend on the standing conditions tested. Particularly, in single-stance with the eyes closed the occurrence of significant correlation is increased compared to the other conditions between the Tibialis Anterior and each of the vertical and medial-lateral force components and between each of the Quadriceps and Gluteus Maximus and the vertical force component. With regards to the center of pressure, the occurrence of significant correlation in single-stance with the eyes closed is increased compared to the other conditions between the Tibialis Anterior and the medial-lateral component and between the Quadriceps and each of the anterior-posterior and medial-lateral components. This suggests that in single-stance standing there is a stronger degree of synchronization between muscle activity and the external force.

The results thus indicate that in 2-leg standing EMG and foot-ground reaction forces signals correlate with each other to a very low extent, whereas under conditions of lower redundancy EMG \& foot-ground reaction forces signals become more correlated together. It should be reminded, though, that the three ankle muscles treated here are not the sole actuators of postural sway. Posture models have dealt with both the ankle and hip joints, each as a two degree-of-freedom joint, thus presenting multi-joint, multi-actuator models. The models were represented by closed-chain and open-chain models for double (Levin and Mizrahi 1996, Levin et al 1998) and single-stance standing (Mizrahi et al 2002), respectively. On the other hand, the correlation between the medio-lateral component of the reaction force and the activity of the three shank muscles is higher than the correlation between the anterior-posterior component of the reaction force and the activity of these muscles. This can be explained by the higher postural sway in the medial-lateral direction compared to the anterior-posterior direction (Table 2).

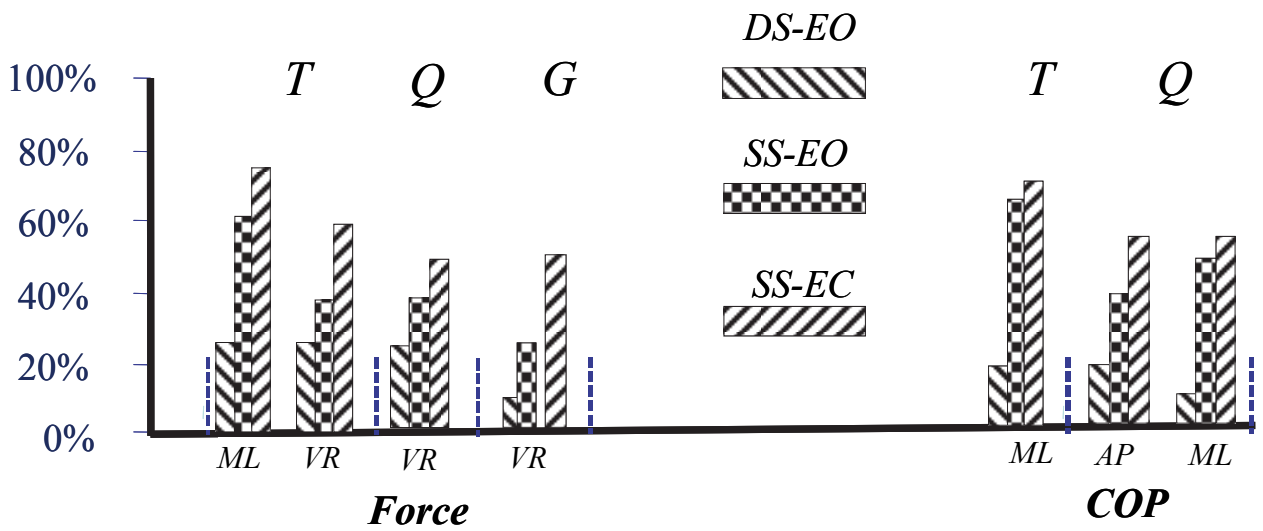

Fig. 4. Occurrence of significant correlation between the root mean square of the footground reaction forces and root mean square of the EMG of three of the leg major muscles: Tibialis anterior (T), Quadriceps (Q) and Gluteus Maximus (G). Each of these muscles is correlated with the components of the foot-ground reaction forces and of the centre of pressure $(\mathrm{COP})$. $\mathrm{DS}=$ double stance; $\mathrm{SS}=$ single stance; $\mathrm{EO}=$ eyes open; $\mathrm{EC}=$ eyes closed; $\mathrm{ML}=$ medial-lateral; $\mathrm{VR}=$ vertical; $\mathrm{AP}=$ anterior-posterior . 


\subsection{Effect of fatiguing of the shank muscles on single-leg-standing balance}

Redundancy can be further reduced by temporarily incapacitating part of the lower leg muscles, through fatiguing. The fatiguing effect on single-stance standing sway dynamics was studied by means of two single-stance standing trials, separated by a quasi-isotonic sustained effort intended to induce fatigue of the Tibialis Anterior and Peroneus muscles (Suponitsky et al, 2008). In the standing trials the following quantities were on-line monitored: (a) force-plate data including ground reaction forces and center of pressure displacements to represent sway-related variables, and (b) EMG signals of the Tibialis Anterior, Peroneus and Gastrocnemius muscles, representing the muscular activity about the ankle joint.

Fatiguing of the dorsi-flexors (Tibialis Anterior and Peroneus) was induced by means of suspending a dead weight of $100 \mathrm{~N}$ on the dorsal aspect through a strap. The sustained effort consisted of holding this weight for 240s, while aiming to steadily maintain the ankle angle at 90 degrees, resulting in a quasi-isometric effort. To facilitate tracking of the ankle angle a goniometer was used to provide on-line visual feedback to the tested subject.

Force-plate and ankle angle data were low-pass filtered using an 8th order Butterworth digital filter with a cutoff frequency of $10 \mathrm{~Hz}$. EMG data were filtered using a band-pass filter $(5-500 \mathrm{~Hz})$ with 8 th order Butterworth digital filter. The traces were thereafter divided into equal segments and the root mean square of each segment was calculated and the obtained vectors were normalized by the total standing time. The obtained root mean square vectors were then interpolated by using cubic spline interpolation. To account for the individual variability in standing time, all vectors (EMG, Ground Reaction Forces and Center of Pressure displacements) were normalized by the total standing time and rescaled to the total number of points. The data collected during the standing trials were normalized as follows: EMG of the muscle signals by the respective maximal voluntary contractions of these muscles, reactive force data by the weight of the tested subject and center of pressure data by the subject's length or width of the foot, as appropriate. This allowed comparing the standing experiments among and between subjects, despite the differences in the standing duration.

During the fatiguing protocol the data obtained from the Tibialis Anterior and Peroneus muscles and from the goniometer were divided into equal segments of $6 \mathrm{~s}$ duration. Root mean square of the EMG and of the goniometer data and mean power frequency of the power spectral density function of the EMG signal for every segment were calculated. Muscle fatigue was determined from the following three parameters: (a) inability to steadily keep the ankle angle in the 90 deg position, i.e., significant drift towards plantar-flexion of the ankle, (b) a significant increase of the EMG root mean square, and (c) a significant decrease of the EMG mean power frequency. The fatigue trend was determined by simple linear regression for the goniometer and EMG data versus time.

The development of fatigue during the $240 \mathrm{~s}$ quasi-isometric effort is illustrated in Figure 5 for the Tibialis Anterior muscle. Linear regression of the root mean square of the EMG signal (time domain) and mean power frequency (frequency domain) indicate a statistically significant increase of EMG root mean square and decrease of EMG mean power frequency. Simple and multiple linear regressions with standard least-squares procedures were used to evaluate the fatigue effects on the relationship between the muscles EMG and the swayrelated parameters in the pre- and post-fatigue conditions. The results are presented in Table 4: Pearson's correlation $r$, pre- and post-load conditions; synergistic activity of the Tibialis Anterior and Gastrocnemius muscles. As the result of fatigue, Muscle/Force 
correlation increased and became higher in the medial-lateral direction compared to the anterior-posterior direction. The simple linear regression slope between root mean square of the reaction forces and the root mean square of the EMG of three shank muscles changed from an insignificant value in the preloading single stance standing trial, to a statistically significant value $(p<0.05)$ in the post-loading standing trial. Multiple correlations in the post-load trials gave moderate and high correlation levels, respectively, between reaction force in the medial-lateral and each of the pairs Tibialis Anterior and Peroneus, and Peroneus and Gastrocnemius muscles with statistically significant slopes $(p<0.05)$. High correlation levels were also obtained between the anterior-posterior force component and each of the following muscle combination: Peroneus and Gastrocnemius, and Tibialis Anterior and Gastrocnemius, with significant slopes $(p<0.05)$.

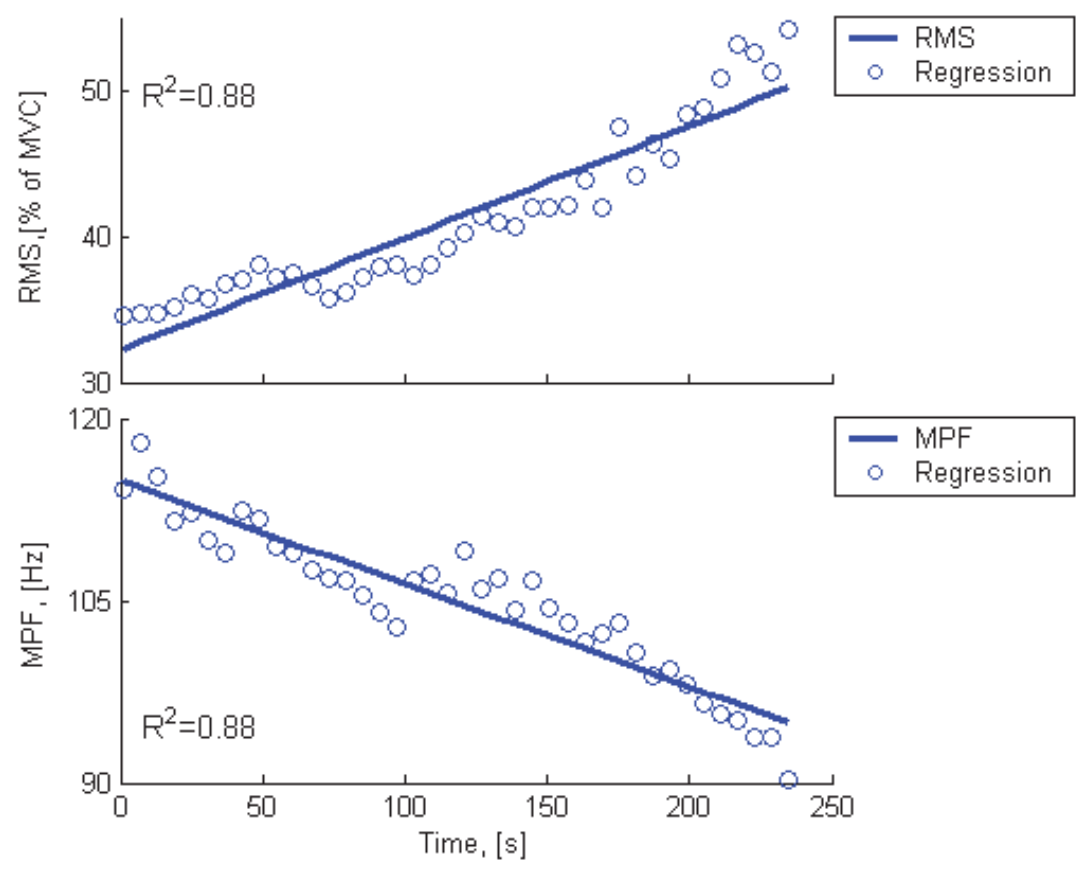

Fig. 5. Development of fatigue of the Tibialis Anterior muscle during the $240 \mathrm{~s}$ quasiisometric effort. Root-mean square (RMS, top) and mean power frequency (MPF, bottom) of the EMG is averaged for five subjects.

\section{Hybrid activation for muscle force enhancement}

\subsection{Partial, or incomplete, deficiency}

Partial muscle force deficiency may be caused by a variety of reasons including, among others, incomplete spinal cord injury, stroke, cerebral palsy, muscle atrophy and ageing. Temporary deficiency may be the result of muscle fatigue [Mizrahi et al, 2000]. With partial deficiency, muscles can still be volitionally activated, although the resulting muscle force may be considerably lower as compared to those of healthy conditions. 


\begin{tabular}{|c|c|c|c|}
\hline \multirow{2}{*}{$\begin{array}{c}\text { Reaction Forces, } \\
\text { vs }\end{array}$} & \multirow{2}{*}{$\begin{array}{l}\text { Pre/Post } \\
\text { Fatigue }\end{array}$} & \multicolumn{2}{|r|}{$\mathrm{r}$} \\
\hline & & $\begin{array}{c}\text { Medial- } \\
\text { lateral }\end{array}$ & Anterior-posterior \\
\hline \multirow{2}{*}{$\begin{array}{l}\text { Tibialis } \\
\text { Anterior }\end{array}$} & Pre-Fatigue & $0.17(0.03)$ & $0.10(0.01)$ \\
\hline & Post- Fatigue & $0.69(0.05)^{*}$ & $0.62(0.02)^{*}$ \\
\hline \multirow[t]{2}{*}{ Peroneal } & Pre- Fatigue & $0.03(0.01)$ & $0.02(0.04)$ \\
\hline & Post- Fatigue & $0.82(0.09)^{* *}$ & $0.73(0.04)^{* *}$ \\
\hline \multirow[t]{2}{*}{ Gastrocnemius } & Pre- Fatigue & $0.06(0.01)$ & $0.17(0.03)$ \\
\hline & Post- Fatigue & $0.88(0.07)^{\star *}$ & $0.69(0.04)^{*}$ \\
\hline \multirow{2}{*}{$\begin{array}{l}\text { Tibialis Anterior \& } \\
\text { Gastrocnemius }\end{array}$} & Pre- Fatigue & & $0.31(0.09)$ \\
\hline & Post- Fatigue & & $0.74(0.14)^{\star *}$ \\
\hline
\end{tabular}

$\mathrm{r}=$ Pearson correlation coefficient

* medium correlation $(\mathrm{r} \sim 0.5-0.7)$

** high correlation $(\mathrm{r} \sim 0.7-0.9)$

Table 4. Linear regression between the EMG signal of the shank muscles and ground reaction forces, before and after fatigue $(\mathrm{ML}=$ medial-lateral component; $\mathrm{AP}=$ anteriorposterior component). All values are RMS [\% MVC], normalized to the subject's weight and represent averages (SD) for all tested subjects

\subsection{The concept of hybrid activation}

Electrical Stimulation (ES) of muscles is a well-known and common technique for the management of muscle force deficiency. While in complete paralysis muscle activation is the result of ES only, in incomplete paralysis muscle activation may generally result from the combined volitional and ES-induced activations. In these latter cases ES is being used for the enhancement of muscle force and for improvement of function and motion of human populations with muscle disabilities [Katz et al 2003, 2008; Langzam et al, 2006a, 2006b, 2007). This modality of muscle activation has been termed hybrid activation (Langzam et al, 2006b), whereby the muscle force results from the combined volitional and electricallyinduced components.

The mechanisms of hybrid activation are not clear. Although the components of this modality were separately investigated and reported, the physiological and mathematical patterns of this added effect are not entirely understood and the question of specific partition of the total muscle torque between these components is recently gaining increasing interest.

\subsection{The partition of total torque into volitional and induced components}

For one thing, hybrid activation can not be considered a simple summation of its components due to possible interactions between them. These interactions may be of the following types: (a) short-term, including reflex inhibition of the antagonistic muscles due to electrical stimulation of the agonistic muscles (Shoji et al, 2005), catch-like effects (BinderMacleod et al, 2002), and stimulus rate modulation (if synchronized with the volitional pulse trains); (b) medium-term effects that can last for minutes after the ES pulse train was stopped, e.g., increased twitch forces (Eom et al, 2002), or enhanced cortico-spinal excitability (Thompson \& Stein, 2004); (c) long-term changes following prolonged training involving strengthening of the muscle and remodulation of its fibers (Katz et al, 2003, 2008). 
Apart from the better understanding of the mechanisms of hybrid activation, a major question of practical nature thus relates to the partition between the volitional and induced torques, within the overall torque. On the practical level, knowledge about the torque components can be readily utilized for muscle contraction manipulation.

In the presence of ES alone, the muscle is known to exhibit a typical recruitment curve (Levy et al, 1990), relating the stimulating current intensity to muscle force. However, when electrical stimulation is applied in addition to volitional activation of the muscle, the ESinduced component may not necessarily obey the recruitment curve displayed under ES alone. Thus, depending on the level of stimulation, the proportion between volitional and induced activations may vary.

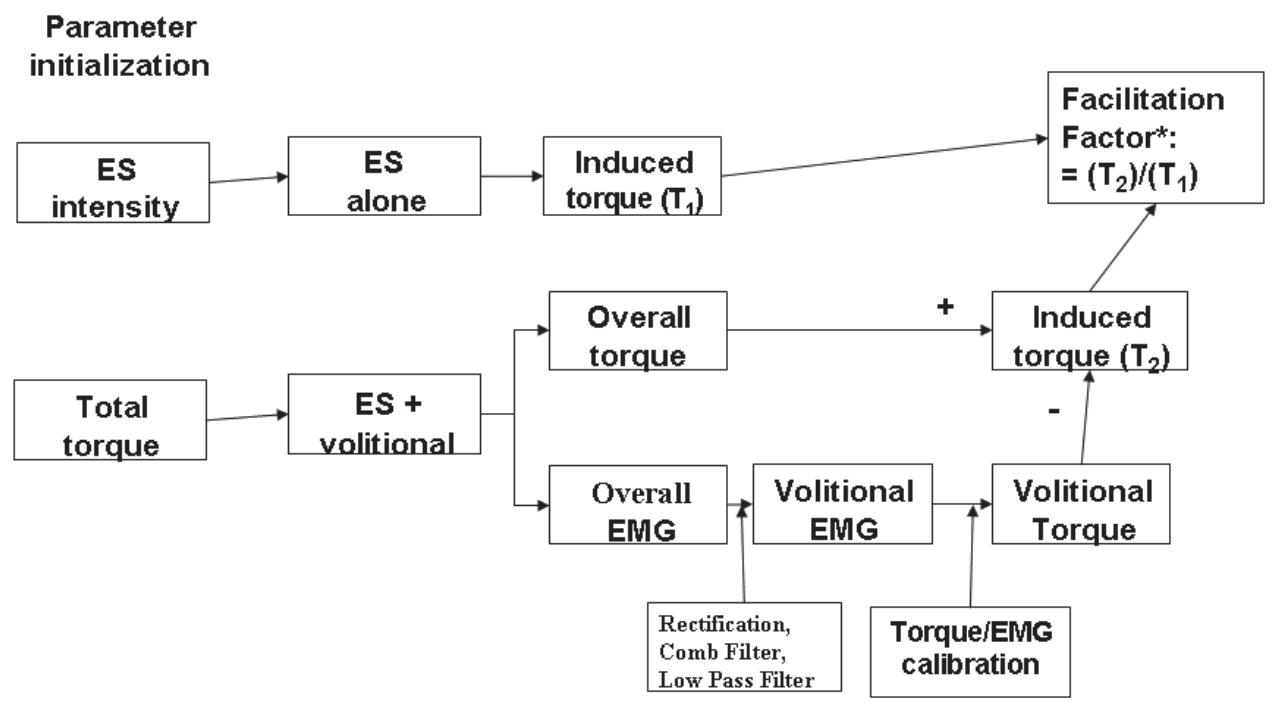

Fig. 6. Procedure for processing the monitored torque and EMG signals and definition of the facilitation factor. More details about the EMG processing are given in Fig. 7.

\subsection{Past and recent works related to hybrid activation}

Characterization of the sharing between the volitional and induced parts of activation has in the past been partly addressed. Early works evaluated the augmentation effect, though without addressing the hybrid operation mode of the muscle (Johnston et al, 2004; Pierce et al, 2004; Thorsen et al, 1999). Additional studies focused on the facilitation of the volitional force due to the accumulated training effect with ES, but did not address the effect of facilitation during stimulation (Katz et al, 2003; Knash et al, 2003; Liron-Keshet et al, 2001; Thompson \& Stein, 2004).

The more recent studies dealing with the actual hybrid modality of activation [Langzam et al, 2006a, 2006b, 2007] go well beyond the previous ones, where the volitional EMG is used solely as a bio-trigger for the external stimulator in a hybrid contraction system (Peasgood et al, 2000; Rakos et al, 1999; Thorsen et al, 1999, 2002). In those recent studies the myoelectric signal assumes a key role. 


\subsection{The role of electromyograms in hybrid activation}

In the recent studies dealing with hybrid activation [Langzam et al, 2006a, 2006b, 2007], the tested subjects were requested to track in real-time a visually displayed torque-time profile by activating the Tibialis Anterior muscle through the application of a dorsi-flexion torque at the ankle. Tracking was made in two modes of activation: 1) purely volitional activation, for calibration and system identification of the volitional component, and 2) hybrid activation, where volitional and ES-induced activations took place simultaneously. The general features of the target torque that the subjects were required to track mimicked different activities the Tibialis Anterior torque, such as observed during human gait. While performing the task, the subject was asked to maintain the torque trace within displayed limits on the feedback screen in front of them. During tracking, the applied ankle torque and the EMG of the Tibialis Anterior muscle were on-line monitored.

The myoelectric signal assumes a major role in dissociating between the volitional and induced torque components. It should be emphasized, however, that apart from specially designed signal processing, signal acquisition necessitates appropriate apparatus and stimulus artifact elimination (Minzly et al, 1993a, 1993b). The monitored signals were thus processed using the procedure outlined in Figure 6. The torque signals were first filtered (4th order Butterworth, cutoff frequency $100 \mathrm{~Hz}$ ). For the EMG signals (Figure 7) a combfilter was used to extract the volitional EMG from the overall raw EMG signals. A comb filter is a simple finite response filter, with adjustable parameters to match the stimulus frequency and to remove the ES component from the compound EMG signal. A more complete description of the filter is given elsewhere (Langzam et al 2006b; Thorsen et al 1999). The volitional EMG was rectified and filtered (4th order Butterworth low pass filter, cutoff frequency $5 \mathrm{~Hz}$ ) to generate the voluntary EMG envelope. Using EMG values (envelope of the rectified signal) in the EMG-torque calibration curve yielded the volitional part of the torque within the total torque.

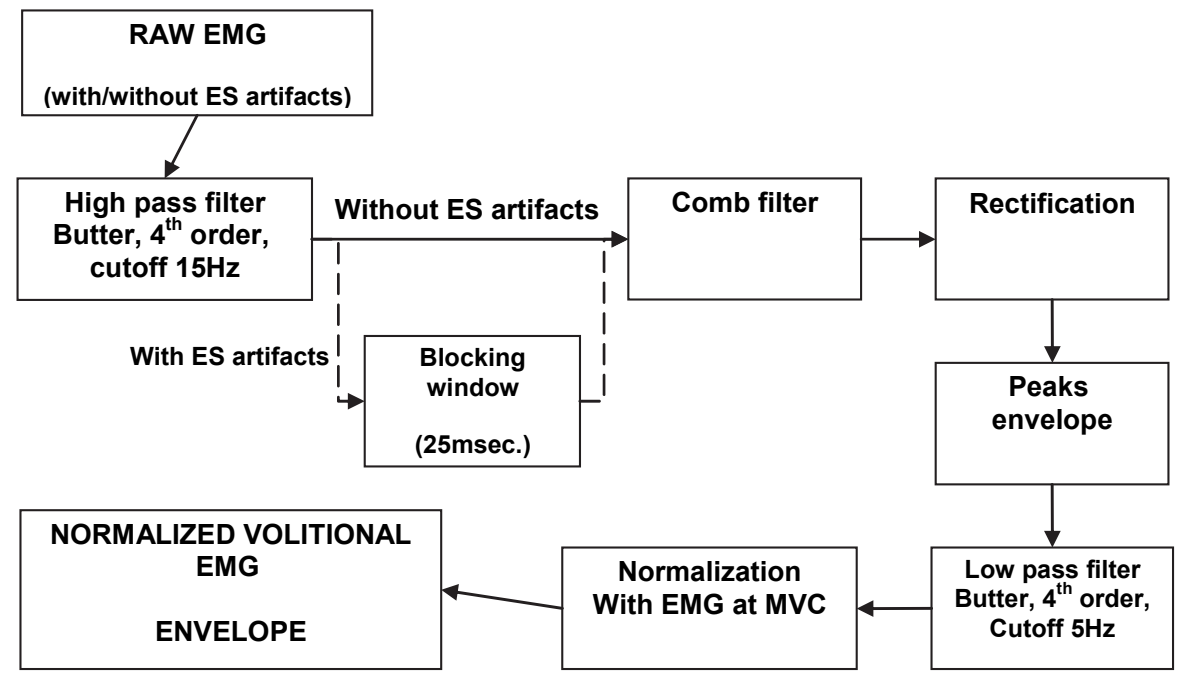

Fig. 7. Procedure used for dissociating between the induced and volitional components of the EMG signal in Hybrid Activation of the muscle. 
The induced torque during hybrid activation was calculated as the difference between the total applied torque and the volitional torque. The obtained induced torque was then converted to current intensity by means of a pre-prepared recruitment calibration curve. This gave the equivalent current intensity, i.e., the intensity that would have produced the same torque during the muscle calibration process. The Facilitation Factor was defined as the ratio between this equivalent intensity and the actual current intensity during the hybrid activation experiment. Facilitation factor values can be greater than, equal, or smaller than one. When greater than one, this means that the equivalent current is greater than the actual stimulation current, therefore the produced induced torque is higher than expected. When the facilitation factor equals one, this means that both equivalent and actual currents are equal; therefore the expected induced torque is actually obtained, and that the electrical stimulation recruitment curve remains unchanged in hybrid compared to isolated stimulation. Facilitation factor lesser than one means that the equivalent current is lower than the actual stimulation current; therefore the produced induced torque is lower than expected. It should be noted that facilitation factors greater or smaller than one indicate that under the hybrid mode of activation, compared to the isolated conditions, changes in the actual stimulation recruitment curves take place.

\subsection{Facilitation factor}

Figure 8 exhibits typical results of the Facilitation Factor. A power regression curve was used to mathematically describe the facilitation factor versus current intensity. Initially, the facilitation factor value starts off at the lower intensity values of 3-6 mA with values greater than unity. Following a gradual decrease, the facilitation factor crosses the unity value termed as unity-crossing which is in this case at the current intensity of $6.5 \mathrm{~mA}$, after which the facilitation factor values become smaller than unity. From this intensity onward, the combined torque effect in hybrid activation is smaller than the algebraic sum of the volitional and the ES-induced, as would have obtained from the recruitment curve. A facilitation factor greater than unity in the lower current range, indicates that muscle force augmentation is cost-effective. Conversely, a facilitation factor smaller than unity at the higher range of current intensity, indicates that augmentation becomes less effective. The results presented in Figure 8 indicate that although the hybrid torque is a linear combination of its volitional and induced components, it is not the simple summation of these components when acting alone. Clearly, the existence of an ES intensity range where the induced torque is enhanced compared to its expected contribution is of practical significance.

Summary of all tested subjects of Facilitation Factor versus ES intensity and of unity crossing is given in Table 5. This summary confirms that the effectiveness of the electricallyinduced contribution in hybrid activation is highly dependent on the stimulation intensity. The facilitation factor parameter sheds light on the intensity ranges in which the effectiveness of the augmentation phenomenon is higher or lower. An increased effectiveness is indicated when torque augmentation exceeds the torque value resulting from the facilitation factor recruitment curve. Such a situation takes place at the lower intensity values.

\subsection{Possible reasons for altered effectiveness of the activation components in Hybrid activation}

Although the reasons for the changed effectiveness of the electrical activation are not clear, several possibilities can be suggested. 


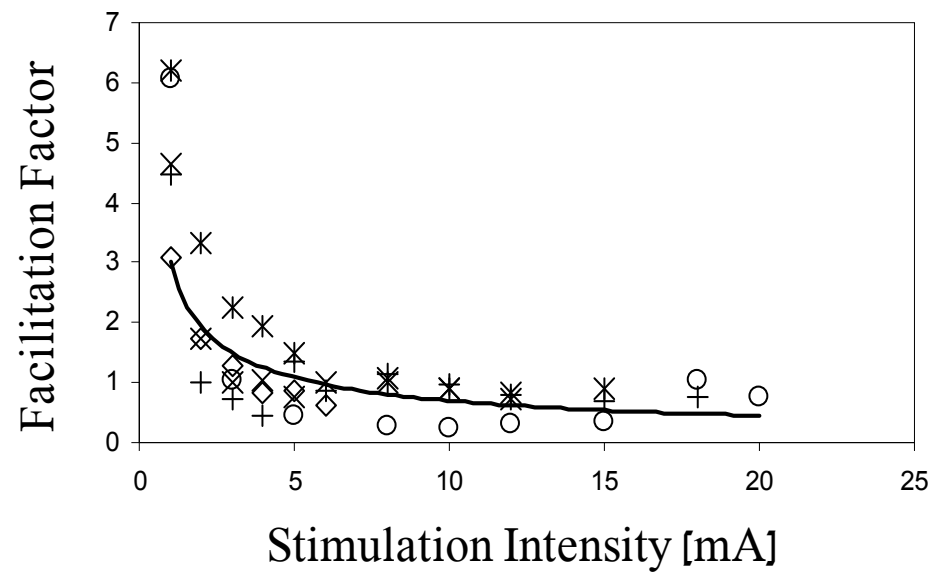

Fig. 8. Typical Facilitation Factor (defined in Fig. 6) as obtained from one subject. The solid curve represents regression of data $\left(y=a x^{b}\right)$. The symbols indicate different testing days of the same subject.

\begin{tabular}{|c|c|}
\hline $\begin{array}{c}\text { Intensity } \\
(\mathrm{mA})\end{array}$ & $\begin{array}{c}\text { Average } \\
(\mathrm{SD})\end{array}$ \\
\hline 1 & $3.52(1.33)$ \\
\hline 5 & $1.41(0.48)$ \\
\hline 10 & $0.96(0.32)$ \\
\hline 15 & $0.77(0.25)$ \\
\hline 30 & $0.52(0.18)$ \\
\hline Unity Crossing & $9.83(5.95)$ \\
\hline
\end{tabular}

Table 5. Summary for tested subjects of Facilitation Factor (defined in Fig. 6) versus stimulation intensity (mA), and of unity crossing.

(a) Mechanical redundancy of the musculo-skeletal system that enables the body to generate a given torque by several different activation patterns.

(b) Lack of specificity of the transcutaneous stimulation technique that may result in possible additional activation of nearby muscles to the Tibialis Anterior muscle itself or coactivation of the antagonistic muscles (Levin et al, 2000b).

(c) Recruitment pattern of an excited muscle that suggests that when both volitional and induced excitations act on the same part of the muscle, the fibers will respond to one excitation only. In hybrid activation mode, part of the muscle fibers may become inactive. Thus, during simultaneous excitation, the torque generated is expected to be lower than the summation of torques obtained when each excitation is performed alone, as there might be a disruption of the volitional excitation of some fibers by the presence of ES. Thus, the excitation preference may well be re-directed in hybrid activation. Besides, the effectiveness of the induced ES contribution is highly dependent on stimulation intensity. A counteracting effect may be facilitation of volitional activation, due to the presence of the induced 
component. This effect has also been reported in the excitation of common peroneal nerve during transcranial magnetic stimulation (Thompson \& Stein, 2004).

(d) Sensory effects of ES: it is likely that the hybrid activation not only directly elicited action potentials in motor axons, but also influenced the discharge of the motor neurons due to the sensory feedback associated with the ES-reflex response (Knash et al, 2003; Thompson \& Stein, 2004).

The above-mentioned factors may thus provide an explanation to the non-additive properties between the volitional and induced torque components under hybrid muscle contraction, i.e., the torque is not the simple summation of its components (when each is acting alone).

Hybrid activation of muscles, combining volitional and ES-assisted excitations, introduces a powerful rehabilitation tool for populations suffering from deficiencies and requiring muscle force augmentation, enabling dynamic enhancement of their muscles. Understanding the interactions between the factors involved in Hybrid muscle activation is crucial to determine the intensity ranges where the ES component is more effective for force enhancement and to indicate the optimal mode of hybrid activation. The computational method presented demonstrates the key role of the myoelectric signals in partitioning the overall total torque obtained in hybrid activation into its two activation components, volitional and ES-induced. The induced torque component was calculated as the difference between overall and volitional torque and, together with the ES intensity-torque calibration data, determined the required intensity profile of the stimulation required for muscle force augmentation.

While the concept of hybrid activation was illustrated on the Tibialis Anterior muscle, it may be generalized to any other muscle. From the measured EMG it has been demonstrated how augmentation of the volitional torque can be computed at any given stimulation level. Conversely, the stimulation level can be indicated for a required force enhancement. The relationships between volitional, induced and overall torques provide the 'torque-lines' that can be used for the quantitative assessment of force enhancement in hybrid stimulation. The ability to predict the stimulation level required to achieve a given force augmentation enables us to better control, track, and analyze behavior and to provide the subject with a more customized, thus effective, treatment.

\section{Conclusion}

The role of electromyography in biomechanics and kinesiology was presented here in the context of redundancies of the neuro-muscular system. These redundancies introduce indeterminacies in the dynamic system, whereby the number of unknowns exceeds the number of available equations, hindering the possibilities to reach the actual physiological solution. It was shown that when redundancies are reduced, the system becomes less indeterminate and at cases it may become unequivocally soluble. It is in these cases where electromyographic data assume a crucial role.

Within the examples given to demonstrate the effects of reduced redundancy, it was shown that EMG data may resolve segment kinematics of the lower limb. This was demonstrated for the ankle joint through the combined activation of the ankle antagonist muscles. Further, the electromyograms were shown to provide indication about posture regulation through increased correlation with the externally measurable reactive forces, in cases of reduced redundancy through single stance standing or through fatiguing of part of the muscles. 
Particularly, the results obtained have demonstrated that muscle fatigue evokes an increased correlation between the activity of the major muscles of the ankle and the sway related parameters, implying that higher levels in the nervous system become more unequivocally related to lower levels. The results thus obtained can serve for the detection of posture disorders in elderly populations or following spinal or lower limb injuries. The resulting activation modes of the muscles can serve as feasible activation modes in cases where functional electrical stimulation is used for the enhancement of muscle forces. The last example dealt with the information that EMG may provide to determine the effectiveness of hybrid activation of handicapped muscles.

\section{Acknowledgement}

This Chapter is partly based on results obtained in the Author's Biomechatronics Laboraory, Department of Biomedical Engineering, Technion - Israel Institute of Technology. The Author acknowledges the contribution of his former collaborators and graduate students, particularly O. Brion, D. Daily, A. Katz, E. Langzam, O. Levin, M. Levy, S. Liron-Keshet, D. Russek and Y. Suponitsky. The study was supported in part by the Israel Ministry of Science and Technology.

\section{References}

Bechtol, C.O. (1975). Normal Human Gait, In: Atlas of Orthotics, J.H. Bowker \& C.B. Hall, (Eds.), pp. 133-143, Mosby, St. Louis.

Bendat, J.S. \& Piersol, A.G. (1970). Random Data: Analysis and Measurement Procedures, Wiley \& sons, Hoboken, NJ, USA.

Binder-Macleod, S. A.; Dean, J. C. \& Ding, J. (2002). Electrical Stimulation Factors in Potentiation of Human Quadriceps Femoris. Muscle Nerve, vol. 25, pp. 271-279.

Bourdin, M.; Belli, A.; Arsac, L.M.; Bosco, C. \& Lacour, J.R. (1995). Effect of vertical loading on energy cost and kinematics of running in trained male subjects. Journal of Applied Physiology, Vol. 79:6, pp. 2078-2085.

Buczek, F.L. \& Cavanagh, P.R. (1990). Stance Phase Knee and Ankle Kinematics and Kinetics during Level and Downhill Running, Med. Sci. Sports Exerc, Vol 22:5, pp. 669-677.

Cavanagh, P.R. (1990). Biomechanics of Distance Running, Human Kinetics Books, Champaign, IL, USA, pp. 165-188.

Colson, S.; Pousson, M.; Martin, A. \& Van Hoecke, J. (1999). Isokinetic Elbow Flexion and Coactivation Following Eccentric Training, J. Electromyography \& Kinesiology, Vol. 9 pp. 13-20.

Daily, D. (1998). Mechanical Factors in Shock Transmission in the Human Body: Effect of Muscle Fatigue". Research Thesis for the Degree of Master of Science (J. Mizrahi and Y. BenHaim supervisors),, Technion, Israel Institute of Technology, Haifa, Israel.

De Luca, C. (1997). The Use of Surface Electromyography in Biomechanics, J. of Applied Biomechanics, Vol. 13, pp. 135-163.

Eom, G. M.; Watanabe, T.; Hoshimiya, N.\& Khang, G. (2002). Gradual Potentiation of Isometric Muscle Force during Constant Electrical Stimulation, Med. Biol. Eng. Comput., Vol. 40, pp. 137-143. 
Genadry, W.F.; Kearney, R.E. \& Hunter, I.W. (1988). Dynamic Relationship Between EMG and Torque at the Human Ankle: Variation with Contraction Level and Modulation, Med Biol Eng Comput, Vol. 26, pp. 489-493.

Giat, Y.; Mizrahi, J. \& Levy, M. (1993). A Muscolutendon Model of the Fatigue Profiles of Paralyzed Quadriceps Muscle under FES, IEEE Trans. Biomed. Eng., Vol. 40, no. 7, pp. 664-674.

IEEE. Programs for Digital Signal Processing. (1979) IEEE Press, John Wiley \& Sons, ISBN-13: 978-0471059622, New York.

Johnston, T. E.; Finson, R. L.; McCarthy, J. J.; Smith, B. T.; Betz, R. R.; \& Mulcahey, M. J. (2004). Use of Functional Electrical Stimulation to Augment Traditional Orthopedic Surgery in Children with Cerebral Palsy, J. Pediatr. Orthop., Vol. 24, pp. 283-291.

Katz, A.; Tirosh, E.; Isakov, E. \& Mizrahi, J. (2003). Below-Threshold FES in CP: Long-Term Training versus Orthosis Effect, 7th Terme Euganee Meeting Rehabil., pp. 233-233, Padova, Italy, June 14-15, 2003.

Katz, A.; Tirosh, E.; Marmur, R. \& Mizrahi, J. (2008). Enhancement of Muscle Activity by Electrical Stimulation in Cerebral Palsy - a Case Control Study. J. Child Neurology, Vol.23, pp. 259-267.

Kellis, E. \& Baltzopoulos, V. (1998). Muscle Activation Differences between Eccentric and Concentric Isokinetic Exercise, Med E Science in Sports and Exercise, Vol.30(11), pp. 1616-1623.

Knash, M. E.; Kido, A.; Gorassini, M.; Chan, K. M. \& Stein, R. (2003). Electrical Stimulation of the Human Common Peroneal Nerve Elicits Lasting Facilitation of Cortical Motor-Evoked Potential, Exp. Brain Res., Vol. 153, pp. 366-377.

Langzam, E., Nemirovsky, Y., Isakov, E., \& Mizrahi, J. (2006a). Partition Between Volitional and Induced Forces in Electrically Augmented Dynamic Muscle Contractions. IEEE Trans. on Neural Systems \& Rehabilitation Engineering, Vol.14, pp, 322-335.

Langzam, E.; Isakov, E. \& Mizrahi J. (2006b). Evaluation of Methods for Extraction of the Volitional EMG in Dynamic Hybrid Muscle Activation, Journal of NeuroEngineering and Rehabilitation, Vol.3, 27.

Langzam, E., Nemirovsky, Y., Isakov, E. \& Mizrahi, J. (2007). Muscle Enhancement Using Closed-Loop Electrical Stimulation: Volitional Versus Induced Torque. J Electromyogr Kinesiol., Vol.17, pp.275-284.

Levin, O. \& Mizrahi, J. (1996). An Iterative Model for the Estimation of the Trajectory of Center of Gravity from Bilateral Reactive Force Measurements in Standing Sway. Gait \& Posture, Vol.4, pp. 89-99.

Levin, O.; Mizrahi, J. \& Shoham, M. (1998). Standing Sway: Iterative Estimation of the Kinematics and Dynamics of the Lower Extremities from Force-Plate Measurements. Biol Cybern, Vol.78, pp. 319-27.

Levin, O.; Mizrahi, J.; Adam, D., Verbitsky, O. \& Isakov, E. (2000a). On the Correlation Between Force Plate Data and EMG in Various Standing Conditions, In: Proceedings of the Fifth Annual Conference of the International Functional Electrical Stimulation Society, T. Sinkjaer, D. Popovic \& J.J. Struijk (Eds), pp. 47-50, Center for SensoryMotor Interaction, Aalborg University, Denmark,. June 18-24, 2000.

Levin, O.; Mizrahi, J. \& Isakov, E. (2000b). Transcutaneous FES of Paralyzed Quadriceps: Is Knee Torque Affected by Unintended Activation of the Hamstrings? J. Electromyogr. Kinesiol, Vol.10, pp. 47-58. 
Levy, M.; Mizrahi, J. \& Suzak, Z. (1990). Recruitment, Force and Fatigue Characteristics of Quadriceps Muscles of Paraplegics, Isometrically Activated by Surface FES. J. Biomed. Eng., Vol.12, pp. 150-156.

Liron-Keshet, S.; Tirosh, E.; Mizrahi, J.; Verbitsky, O.; Isakov, E.; Marmur, R. \& Rabino, S. (2001). The Effect of Therapeutic Electrical Stimulation in Children with Diplegic Cerebral Palsy as Measured by Gait Analysis. Basic Appl. Myol., Vol. 11, pp. 127132.

Marple-Horvat, D.E. \& Gilbey, S.L. (1992). A Method for Automatic Identification of Periods of Muscular Activity from EMG Recordings. J. of Neuroscience Methods, Vol. 42, pp. 163-167.

Minzly, J.; Mizrahi, J.; Hakim, N. \& Liberson, A. (1993a). Stimulus Artifact Suppressor for EMG Recordings during FES by Constant-Current Stimulator. Med Biol Eng Comput, Vol.31(1), pp. 72-75.

Minzly, J.; Mizrahi, J.; Isakov, E.; Susak, Z., \& Verbeke, M. (1993b). Computer-Controlled Portable Stimulator for Paraplegic Patients. J Biomed Eng, Vol.15(4), pp. 333-338.

Mizrahi, J. (2004). Muscle/Bone Interactions in the Musculo-Skeletal System. Published by the Center of Excellence for Applied Biomedical Modelling and Diagnostics, Warsaw, ISSN 1733-0874.

Mizrahi, J., Brion, O. and Adam, D. (2002) Open-Chain analysis of single stance. J. Automatic Control, 12: 46-55.

Mizrahi, J.; Levy, M.; Ring, H.; Isakov, E. \& Liberson, A. (1994). EMG as an Indicator of Fatigue of Isometrically FES-Activated Paralyzed Muscles. IEEE Trans. Rehab. Eng., Vol.2, pp. 57-65.

Mizrahi, J.; Verbitsky, O.; Isakov, E. \& Daily, D. (2000). Effect of Fatigue on Leg Kinematics and Impact Acceleration in Long Distance Running. Human Movement Science, Vol.19 (2), pp. 139-151.

Mizrahi, J.; Verbitsky, O. \& Isakov, E. (2001). Fatigue-Induced Changes in Decline Running, Clin Biomech, Vol.16 (3), pp. 207-212.

Mizrahi, J. \& Susak, Z. (1989). Bilateral Reactive Force Patterns in Postural Sway Activity of Normal Subjects. Biol Cybern, Vol.60, pp. 297-305.

Nardone, A.; Tarantola, J.; Giordano, A. \& Schieppati, M. (1997). Fatigue Effects on Body Balance. Electroen Clin Neuro, Vol.105, pp. 309-20.

Nilsson, J.; Thorstensson, A. \& Halbertsma, J (1985). Changes in the Leg Movements and Muscle Activity with Speed of Locomotion and Mode of Progression in Humans. Acta Physiol. Scand, Vol.123 (4), pp. 457-475.

Oppenheim, A.V. \& Schafer, R.W. (1975). Digital Signal Processing, Prentice-Hall, Saddle River, NJ.

Peasgood, W.; Whitlock, T.; Baman, A.; Fry, M.E.; Jones, R.S. \& Davis-Smith, A. (2000). EMG-Controlled Closed Loop Electrical Stimulation Using Digital Signal Processor. Electron Lett, Vol.36(22), pp.1832-1833.

Patriarco, A.G.; Mann, R.W.; Simon, S.R.; \& Mansour, J.M. (1981). An Evaluation of the Approaches of Optimization Models in the Prediction of Muscle Forces During Human Gait. J Biomech., Vol.14, pp. 513-525.

Peng, C.W.; Chen, S.C.; Lai, C.H.; Chen, C.J.; Chen, C.C.; Mizrahi, J. \& Handa, Y. (2011). Clinical Benefits of Functional Electrical Stimulation Cycling Exercise for Subjects with Central Neurological Impairments: Review, Journal of Medical and Biological Engineering, 31(1), pp. 1-11. 
Pierce, S. R.; Laughton, C. A.; Smith, B. T.; Orlin, M. N.; Johnston, T. E. \& McCarthy, J. J. (2004). Direct Effect of Percutaneous Electrical Stimulation During Gait in Children with Hemiplegic Cerebral Palsy: A Report of 2 Cases. Arch. Phys. Med. Rehabil., Vol.85, pp. 339-343.

Prilutsky, B.I.; Gregor, R.J. \& Ryan, M.M. (1998). Coordination of Two-Joint Rectus Femoris and Hamstrings during the Swing Phase of Human Walking and Running. Exp. Brain Res., Vol.120, pp. 479-486.

Rakos, M.; Freudenschuss, B.; Girsch, W.; Hofer, C.; Kaus, J.; Meiners, T.; Paternostro, T. \& Mayr, W. (1999). Electromyogram-Controlled Functional Electrical Stimulation for Treatment of Paralyzed Upper Extremity. Artif Organs, Vol.23(5), pp. 466-469.

Russek, D. (2002). The Relation between EMG and Kinematics in Running Fatigue, MSc Thesis (J. Mizrahi supervisor), Library System No. 002246490, Technion, Israel Institute of Technology, Haifa, Israel.

Saxena, S.; Nikolic, S. \& Popovic, D. (1995). An EMG-Controlled System for Tetraplegics. J Rehabil Res Dev, Vol.32 (1), pp. 17-24.

Shoji, J.; Kobayashi, K.; Ushiba, J.; Kagamihara, Y. \& Masakado, Y. (2005). Inhibition from the Plantar Nerve to Soleus Muscle during the Stance Phase of Walking. Brain Res., Vol.1048, pp. 48-58.

Shumway-Cook, A.; \& Woollacott, M. (1995). Motor Control: Theory and Practical Applications, Williams \& Wilkins, Baltimore, MD.

Suponitsky, Y., Verbitsky, O., Peled, E., and Mizrahi J. (2008) Effect of Force Imbalance of the Shank Muscles, due to Selective Fatiguing, on Single-Leg-Standing Control, J. Electromyography and Kinesiology, 18:682-689.

Tamaki, H.; Kitada, K. \& Akamine, T. (1997). Electromyogram Patterns during Plantarflexions at Various Angular Velocities and Knee Angles in Human Triceps Surae Muscles. Eur. J. Appl. Physiology, Vol.75, pp. 1-6.

Thompson, K. \& Stein, R. B. (2004). Short-term effects of functional electrical stimulation on motor-evoked potentials in ankle flexor and extensor muscles. Exp. Brain Res., Vol.159, pp 491-500.

Thorsen, R.; Ferrarin, M.; Spadone, R. \& Frigo, C. (1999). Functional Control of the Hand in Tetraplegics Based on Residual Synergistic EMG Activity. Artif Organs, Vol.23(5), pp. 470-473.

Thorsen, R.; Spandone, R. \& Ferrarin, M. (2001). A Pilot Study of Myoelectrically Controlled FES of Upper Extremity. IEEE Trans Neural Syst Rehabil Eng, Vol.9 (2), pp. 161-168.

Thorsen, R.; Ferrarin, M. \& Veltink, P. (2002). Enhancement of Isometric Ankle Dorsiflexion by Automyoelectrically Controlled Functional Electrical Stimulation on Subjects with Upper Motor Neuron Lesions. Neuromodulation, Vol.5 (4), pp. 256-263.

Tropp H, Odenrick P. Postural control in single-limb stance. J Orthopedic Res 1988;6:833-9.

Vuillerme, N.; Danion, F.; Forestier, N. \& Nougier, V. (2002). Postural Sway Under Muscle Vibration and Muscle Fatigue in Humans. Neurosci Lett, Vol.333, pp. 131-5.

Winter, D.; Prince, F.; Frank, J.; Powell, C. \& Zabjek, K. (1996). Unified Theory Regarding A/P and M/L Balance in Quiet Stance. J Neurophysiol, vol.75, pp. 2334-43.

Winter, D.A. \& Scott, S.H. (1991). Technique for Interpretation of Electromyography for Concentric and Eccentric Contractions in Gait. J. of Electromyog. and Kinesiol., Vol.1(4), pp. 263269.

Yaggie, J. \& McGregor, S. (2002). Effects of Isokinetic Ankle Fatigue on the Maintenance of Balance and Postural Limits. Arch Phys Med Rehabil, Vol.83, pp. 224-8. 


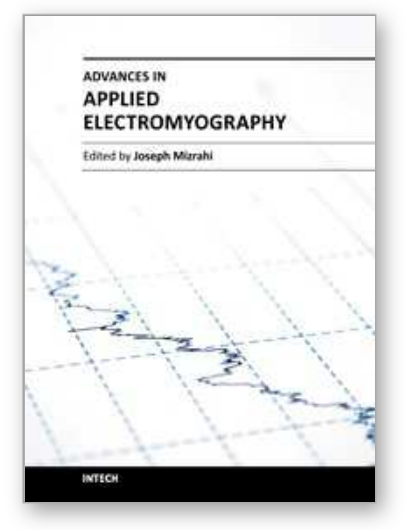

\author{
Advances in Applied Electromyography \\ Edited by Prof. Joseph Mizrahi
}

ISBN 978-953-307-382-8

Hard cover, 212 pages

Publisher InTech

Published online 29, August, 2011

Published in print edition August, 2011

The electrical activity of the muscles, as measured by means of electromyography (EMG), is a major expression of muscle contraction. This book aims at providing an updated overview of the recent developments in electromyography from diverse aspects and various applications in clinical and experimental research. It consists of ten chapters arranged in four sections. The first section deals with EMG signals from skeletal muscles and their significance in assessing biomechanical and physiologic function and in applications in neuro-musculo-skeletal rehabilitation. The second section addresses methodologies for the treatment of the signal itself: noise removal and pattern recognition for the activation of artificial limbs. The third section deals with utilizing the EMG signals for inferring on the mechanical action of the muscle, such as force, e.g., pinching force in humans or sucking pressure in the cibarial pump during feeding of the hematophagous hemiptera insect. The fourth and last section deals with the clinical role of electromyograms in studying the pelvic floor muscle function.

\title{
How to reference
}

In order to correctly reference this scholarly work, feel free to copy and paste the following:

J. Mizrahi (2011). The Role of Electromyograms in Resolving Musculoskeletal Interactions in Able-Bodied and Disabled Human Individuals, Advances in Applied Electromyography, Prof. Joseph Mizrahi (Ed.), ISBN: 978953-307-382-8, InTech, Available from: http://www.intechopen.com/books/advances-in-appliedelectromyography/the-role-of-electromyograms-in-resolving-musculoskeletal-interactions-in-able-bodied-anddisabled-hu

\section{INTECH}

open science | open minds

\section{InTech Europe}

University Campus STeP Ri

Slavka Krautzeka 83/A

51000 Rijeka, Croatia

Phone: +385 (51) 770447

Fax: +385 (51) 686166

www.intechopen.com

\section{InTech China}

Unit 405, Office Block, Hotel Equatorial Shanghai

No.65, Yan An Road (West), Shanghai, 200040, China 中国上海市延安西路65号上海国际贵都大饭店办公楼405单元

Phone: +86-21-62489820

Fax: +86-21-62489821 
(C) 2011 The Author(s). Licensee IntechOpen. This chapter is distributed under the terms of the Creative Commons Attribution-NonCommercialShareAlike-3.0 License, which permits use, distribution and reproduction for non-commercial purposes, provided the original is properly cited and derivative works building on this content are distributed under the same license. 